\title{
IMPLEMENTASI FATWA-FATWA DSN-MUI PADA PEMBIAYAAN DANA TALANGAN HAJI (STUDI KASUS PADA PADA KSPPS BTM MULIA BABAT - LAMONGAN)
}

\author{
Ahmad Arif Rahman Saidi \\ Warsidi \\ Universitas Muhammadiyah Surabaya \\ Email: awam.arifrahman@ gmail.com
}

\begin{abstract}
The use of religious guidances from DSN-MUI as a basis of delivering products in the Micro-Sharia Financial Institution (LKS) is not accompanied by a complete and correct understanding of the implementation. It can be seen in among others, the fund financing of hajj bailout. There are many different kinds of contracts used by micro-sharia financial institution in the hajj bailout fund financing, such as the contract of qardh bil ujrah and ijarah multijasa, even there are those that uses murabahah contract in the hajj fund financing.

The author's interest in examining the implementation of hajj bailout fund financing in KSPPS BTM Mulia is because the KSPPS BTM Mulia used the contract of qardh bil ujrah and then change it into ijarah multijasa at the beginning of the emergence of the product of hajj bailout fund financing. The author intends to find out about the implementation in KSPPS BTM Mulia, which contract is most in accordance with the Sharia economic law, and what are the impact of the changes for KSPPS BTM Mulia.

This study is a qualitative-descriptive research which uses the data collection technique with observation, interview, and documentation. The data source of this study is: (1) the person who is involved in hajj fund financing in KSPPS BTM Mulia starting from the management, Sharia supervisory board, marketing, legal, and customers; and (2) contract documents, minutes of meetings, and other documents which related to and needed in this study.

From this study, it is known that the implementation of hajj bailout fund financing in KSPPS BTM Mulia that uses the qardh bil ujrahcontract, the halal status cannot be guaranteed, while the ijarah multijasa contract with little improvement will be more appropriate and in accordance with the Islamic Sharia principles.
\end{abstract}

Keywords :Hajj Bailout Fund Financing, Contract ofQardh ,Ijarah Multijasa, Kafalah

\section{Pendahuluan}

Lembaga Keuagan Syariah (untuk selanjutnya disebut LKS) yang merupakan bagian dari industri keuangan mikro juga mendapatkan perhatian dari beberapa peneliti di dunia. Di dalam buku the Economics of Microfinance (Armendariz,
2007) ${ }^{1}$ mengungkapkan beberapa mitos terkait keuagan mikro di antaranya : Pertama, bahwa inti dari keuangan mikro hanyalah seputar pemberian pinjaman. Padahal keuangan mikro juga mengakomodir hal lain selain pinjaman

\footnotetext{
1 Darsono, Ferry Syaifuddin, Ali Sakti, Enny Tin Suryanti, Peta Keuangan Mikro Syariah Indonesia, (Jakarta: Tazkia, 2018), Hal. 3.
} 
seperti menabung, asuransi dan lain sebagainya. Kedua, Kesuksesan atas tingkat pengembalian pembiayaan sangat tergantung pada model bisnis group atau tanggung renteng yang terkenal digunakan di Grameen Bank, Bangladesh.Ketiga, Keuangan mikro telah memiliki catatan yang tak terelakkan sebagai alat pengentasan kemisikinan dan pemberdayaan masyarakat yang dilayani, namun keuangan mikro bukanlah obat mujarab ataupun tombol ajaib yang bisa atau selalu dapat menyelesaikan masalah keuangan masyarakt kecil diamana saja dan kapan saja.

Seiring dengan tumbuh pesatnya LKSLKS di Indonesia maka dibutuhkanlah suatu lembaga yang bisa berperan untuk mengarahkan dan menjamin agar transaksi transaksi yang ada di LKS-LKS tersebut tidak melenceng dari kaidah-kaidah syariah yang ada, maka dibentuklah Dewan Syariah. Dewan Syariah merupakan sebuah lembaga yang berperan dalam menjamin ke-Islaman keuangan syariah di seluruh dunia. Di Indonesia, peran ini dijalankan oleh Dewan Syariah Nasional (DSN) yg dibentuk oleh Majelis Ulama Indonesia (MUI) pada tahun 1998 dengan dikukuhkannya SK oleh Dewan Pimpinan MUI No. Kep754/MUI/II/1999 tanggal 10 Februari 1999. DSN-MUI bertugas menangani masalahmasalah yang berkaitan dengan ekonomi syariah, baik yang berhubungan langsung dengan lembaga keuangan syariah ataupun lainnya.

Sejarah berdirinya DSN-MUI berawal dari pesatnya perkembangan keuangan syariah di Indonesia, di mana sebelum adanya DSN-MUI belum ada regulasi resmi yang mengatur operasional lembaga keuangan syariah agar berjalan sesuai prinsip-prinsip syariat Islam. Persoalan muncul karena institusi regulator yang mempunyai otoritas mengatur dan mengawasi lembaga keuangan syariah, yaitu Bank Indonesia (BI) dan kementrian keuangan tidak dapat melaksanakan otoritasnya di bidang syariah. Kedua lembaga pemerintahan tersebut tidak memiliki otoritas untuk merumuskan prinsip-prinsip syariah secara langsung dari teks-teks keagamaan. Berdasarkan hal teresebut, melalui serangakain kegiatan kerjasama MUI dan bank Indonesia maka terbentuklah DSN-MUI pada tahun 1998.

DSN-MUI mulai mendapat legitimasi dari Bank Indonesia yang merupakan lembaga negara pemegang otoritas dibidang perbankan, saat terbitnya Surat Keputusan Direksi Bank Indonesia Nomor 32/34/1999, di mana pd pasal 31 dinyatakan: "untuk melaksanakn kegiatan-kegiatan usahanya, bank umum syariah diwajibkan memperhatikan fatwa DSN".

Berdasarkan uraian tersebut di atas, maka dapat dikatakan bahwa DSN-MUI merupakan satu-satunya lembaga yang diberi amanat oleh undang-undang untuk menetapkan fatwa tentang ekonomi dan keuangan syariah, juga merupakan lembaga yang didirikan untuk memberikan ketentuan hukum islam kepada lembaga keuangan syariah dalam menjalanan aktivitasnya. Ketentuan tersebut sangatlah penting dan menjadi dasar hukum utama dalam perjalanan operasinya.

Pada Jurnal ini penulis tertarik meneliti implementasi pembiayaan talangan haji pada Koperasi Simpan Pinjam dan Pembiayaan Syariah (KSPPS) Baitul Tamwil Muhammadiyah (BTM) Mulia Babat Lamongan, untuk selanjutnya dalam tulisan pada jurnal ini penyebutannya di singkat menjadi KSPPS BTM Mulia Babat Lamongan.

Ketertarikan penulis meneliti implementasi pembiayaan talangan haji pada KSPPS BTM Mulia Babat - Lamongan ini bersumber pada observasi awal penulis terhadap BTM Mulia, di mana terdapat perubahan akad pembiayaan talangan haji yang semula menggunakan akad Qardh 
sebagaimana Fatwa DSN MUI Nomor: 29/DSN-MUI/VI/2002 tentang Pembiayaan Pengurusan Haji Lembaga Keuangan Syariah, yang kemudaian dalam perjalannya KSPPS BTM Mulia mengganti akad tersebut dengan akad Multijasa sebagaimana Fatwa DSN MUI Nomor: 44/DSNMUI/VIII/2004 tentang Pembiayaan Multijasa. Penulis bermaksud menemukan diantara kedua akad tersebut, akad mana yang lebih sesuai dan diterima oleh nasabah dan juga pelaksana operasional lapangan untuk diterapkan pada pembiayaan dana talangan haji di KSPPS BTM Mulia ini.

Berdasar permasalahan yang sudah dituliskan di atas, maka penulis bermaksud membuat penelitian di KSPPS BTM MULIA Babat - Lamongan mengenai akad - akad yang digunakan dalam pembiayan dana talangan pelunasan Biaya Perjalanan Ibadah Haji (BPIH). Dimana penelitian ini meliputi :

1. Bagaimana implementasi pembiayaan dana talangan haji pada KSPPS BTM Mulia Babat - Lamongan

2. Bagaimanakah tinjauan hukum ekonomi syariah terhadap implementasi pembiayaan dana talangan haji pada KSPPS BTM Mulia Babat - Lamongan.

3. Bagaimana dampak perubahan akad pada pembiayaan dana talangan haji pada KSPPS BTM Mulia Babat - Lamongan.

Manfaat penelitian ini secara teoretis adalah bahwa hasil dari penelitian ini diharapkan dapat menjadi rujukan bagi para akademisi untuk kepentingan pengembangan pemikiran sains di bidang hukum ekonomi syariah, khususnya yang berkaitan dengan masalah penerapan prinsip-prinsip syariah pada akad-akad pembiayaan yang dilakukan oleh lembaga-lembaga keuangan syariah, penelitian ini diharapkan, setidaknya memperkaya perbendaharaan konsep tentang akad- akad yang biasa digunakan pada produk talangan pelunasan Biaya Perjalanan Ibadah Haji (BPIH). Sedangkan Manfaat penelitian ini secara praktis adalah diharapakan hasil penelitian ini dapat menjadi landasan pengetahuan bagi masyarakat secara luas yaitu :

a. Manfaat bagi Lembaga Keuangan Mikro Syariah, diharapkan LKS yang ada bisa menggunakan secara praktis akad yang tepat dan benar dalam pembiayaan Talangan Haji, sehingga tidak melanggar ketetapan syariah yang ada

b. Nasabah Pembiayaan Talangan Haji. Diharapkan nasabah tidak terjebak dalam pembiayaan haji yang salah secara hukum syariah, padahal haji sangat terkait erat dengan ibadah syariah

\section{Metode Penelitian}

Penelitian ini termasuk jenis penelitian kualitatif. Dalam penelitian ini peneliti meninjau langsung terhadap subjek penelitian yaitu KSPPS BTM Mulia BabatLamongan. Tujuan observasi tersebut untuk mendapatkan data langsung dari implementasi pengelolaan pembiayaan talangan haji yang ada di KSPPS BTM Mulia tersebut. Selain itu peneliti juga membandingkan beberapa penerapan pembiayaan talangan haji di beberapa LKS yang ada bersumber dari wawancara marketing LKS dan beberapa referensi jurnal lainnya.

Sumber data bayak didapat oleh peneliti dari wawancara dan dokumentasi berkas yang diperoleh dari : 2 orang Dewan Pengawas Syariah (Bersertifikat MUI), ketua dan anggota pengurus koperasi, manajer operasional koperasi serta marketing koperasi (KSPPS BTM Mulia). Beberapa data juga didapat dari nasabah pembiayaan Talangan Haji. Dalam hal ini peneliti mengumpulkan dokumentasi yang berkaitan dengan Akad akad dana talangan haji yang menggunakan akad Qardh dan Akad akad dana talangan haji yang menggunakan akad Ijarah Multijasa. Juga 
dokumen dokumen berupa notulen rapat terkait dengan perubahan akad yang dilakukan terhadap pembiayaan haji. Tujuan dari dokumentasi tersebut adalah untuk mengetahui apa yang menyebabkan perubahan akad dan seberapa besar dampak perubahan akad ini kepada kenyaman nasabah dalam berakad maupun kenyaman pihak Marketing dan karyawan dari KSSPS BTM Mulia dalam berakad.

\section{Hasil dan Pembahasan}

\subsection{Profil Obyek Penelitian}

KSPPS BTM Mulia ((Koperasi Simpan Pinjam dan Pembiayaan Syariah Baitul Tamwil Muhammadiyah) adalah salah satu Amal Usaha milik Muhammadiyah di bawah Pimpinan Cabang Muhammadiyah (PCM) Babatyang didirikan pada 11 Nopember 2009 dan mulai beroperasi tepat 1 Januari 2010.

Inisiatif pendirian BTM Mulia ini berawal dari keprihatinan PCM Babat atas banyaknya rentenir / bank titil yang ada di Babat, terutama di Pasar Babat. Di sisi lain, PCM Babat yang nota bene merupakan PCM yang mengelola banyak amal usaha melihat bahwa AUM yang ada di bawah PCM Babat mengelola dan memiliki dana yang cukup banyak dan dana tersebut banyak ditempatkan di bank-bank umum yang ada di Babat. Selain itu warga Muhammadiyah di Babat diyakini juga banyak yang memiliki dana yang ditempatkan di bank bank umum tersebut. PCM Babat melihat hal ini merupakn potensi besar untuk di berdayakan dan akan bisa memberikan manfaat lebih baik untuk Persyarikatan Muhammadiyah maupun untuk masyarakat pada umumnya.
Berikut Tabel profil BTM Mulia :

Gambar 3.1

Profil KSPPS BTM Mulia

KOPERASI SIMPAN PINJAM PEMBIAYAAN SYARIAH

BAITUL TAMWIL MUHAMMADIYAH "MULIA" BABAT

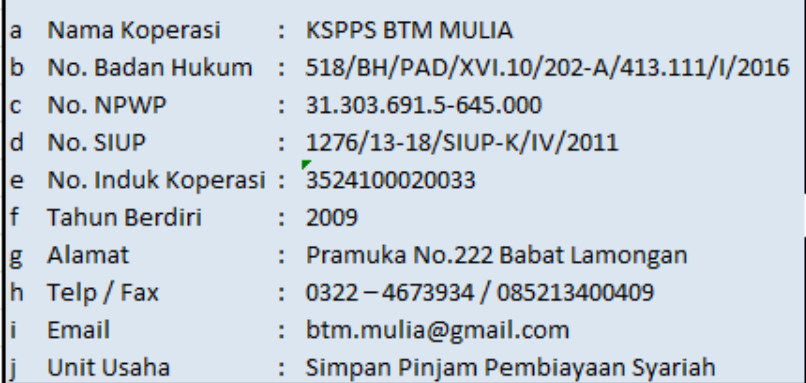

Gambar 3.2

Pertumbuhan Aset KSPPS BTM Mulia

Pertumbuhan Aset BTM Mulia

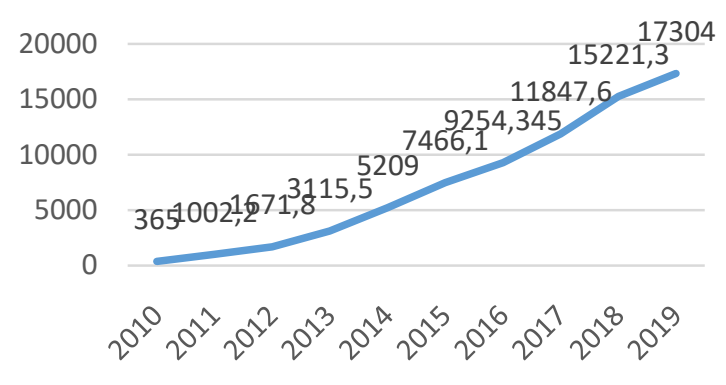

Gambar 3.3

Pertumbuhan SHU KSPPS BTM Mulia

Pertumbuhan SHU BTM Mulia

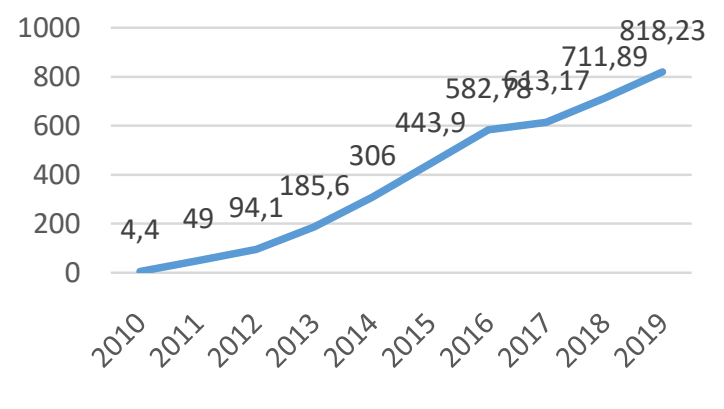

Gambar 3.4 
Pertumbuhan Pembiayaan KSPPS BTM Mulia

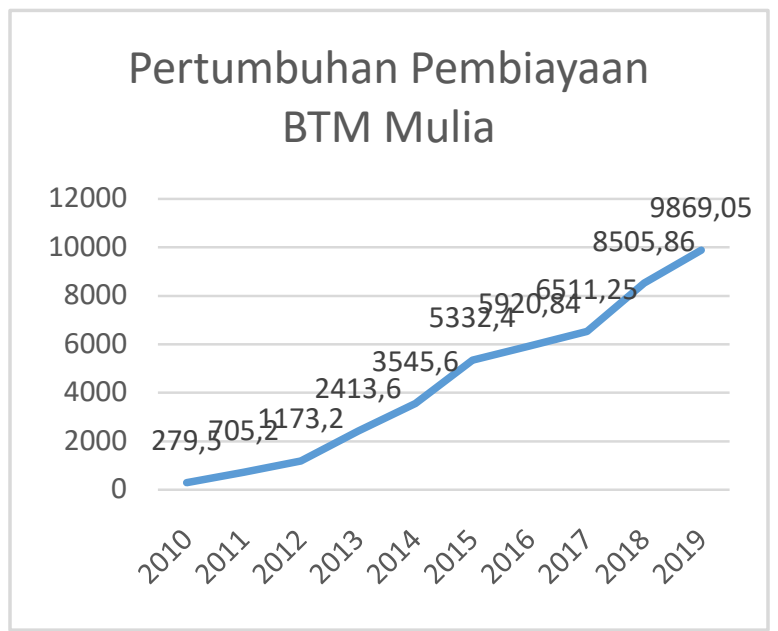

\subsection{Sejarah dan Latar Belakang Pembiayaan Talangan Haji di KSPPS BTM Mulia}

Sejarah dan awal mula dikeluarkannya produk talangan haji di KSPPS BTM Mulia ini berawal dari permintaan salah seorang anggota koperasi KSPPS BTM Mulia yang selama ini dianggap loyal dan bagus pembayaran cicilannya, di mana anggota tersebut ingin mendaftarkan diri untuk mendapatkan porsi haji akan tetapi belum mempunyai uang yang cukup. Permasalahn ini kemudian oleh nasabah tersebut disampaikan kepada marketing KSPPS BTM Mulia Saudari Irhamni.Selanjutnya pada rapat bulanan KSPPS BTM Mulia pada tanggal 04 Desember 2015 (dokumen notulen rapat terlampir) diputuskanlah untuk mengadakan produk talangan haji.

Selanjutnya dirancanglah produk talangan haji dengan menggunakan akad qardh sesuai dengan fatwa DSN-MUI Nomor 29/DSN-MUI/VI/2002 Tentang Pembiayaan Pengurusan Haji Lembaga Keuangan Syariah.

Dalam perjalannya penggunaan akad ini menemui beberapa masalah. Permasalahan yang timbul sebagaimana disampaikan kepada penulis oleh Saudari Ari Purwanti selaku Manajer Operasional pada wawancara 05 November 2019 di KSPPS BTM Mulia dapat di rangkum sebagai berikut :

a) Komplain dari Nasabah

Beberapa nasabah yang kritis dan peduli pada kehalalan suatu akad banyak memberikan masukan terkait akad Qardh bil Ujrah pada pembiayaan talangan haji ini. Dalam prakteknya masih terdapat keraguan akan kehalalan produk ini. Di mana dalam produk dana talangan haji ini ada dua akad yang digabungkan dalam sebuah produk, yaitu akad qardh (pinjam meminjam) dan akad Ijarah (jual beli jasa) dalam bentuk ujrah (fee administrasi dan fee pengurusan). Walaupun pada fatwanya DSN-MUI sudah mengisaratkan bahwa akad qardh pada pembiayaan talangan haji adalah terpisah dari akad ijarah-nya. Dan juga ditegaskan pada ketentuan umum fatwa tersebut bahwa besar imbalan jasa al-Ijarah tidak boleh didasarkan pada jumlah talangan al-Qardh yang diberikan LKS kepada nasabah

b) Kesulitan Marketing

Marketing sebagai ujung tombak KSPPS BTM Mulia memegang peran penting dalam jumlah pembiayaan-pembiayaan yang ada di KSPPS BTM Mulia ini. Dengan adanya keraguan akan kehalalan akad qardh bil ujrah ini berdampak pada kinerja marketing. Marketing relatif enggan memasarkan produk pembiayaan haji ini.Dan juga marketing mengalami kesulitan apabila menjawab pertanyaan-pertanyaan calon nasabah terkait pembiayaan talangan haji ini.

Dari permasalahan-permasalahan yang ada di lapangan tersebut terkait implementasi pembiayaan talangan haji dengan akad qardh maka pada rapat bersama Pengurus - Pengawas dan Dewan Pengawas Syariah KSPPS BTM Mulia pada tanggal 14 Oktober 2017 disepakati untuk merubah akad pembiayaan talangan haji qardh dan 
menggunakan akad pembiayaan talangan haji dengan prinsip Ijarah Multijasa sebagaimana Fatwa DSN-MUI Nomor: 44/DSN-MUI/VIII/2004 Tentang Pembiayaan Multijasa

Dampak dari perubahan akad pembiayaan talangan haji tersebut bagi pelaksana lapangan dirasakan cukup bagus. Berdasar wawancara penulis dengan beberapa pelaksana lapangan yaitu Manajer Operasional Ari Purwanti, Koordinator Marketing Irhamni, Customer service Dwi Zaid dan Legal Saudari Widyastuti Dyah Purwandari dapat disimpulkan sebagai berikut :

a) Komplain dan protes dari nasabah terkait kehalalan produk talangan haji hampir tidak ada. Nasabah merasa lebih nyaman dengan akad Ijarah Multijasa ini

b) Marketing lebih percaya diri dan nyaman dengan akad Ijarah Multijasa ini karena beranggapan bahwa akad ini tidak mengandung unsur riba disebabkan jelasnya Obyek manfaat dari Ijarah

c) Diperoleh data ternyata dengan perubahan akad ini berdampak pada meningkatnya jumlah nasabah pembiayaan talangan haji, dimana pada penggunaan akad qardh hanya terdapat 22 nasabah dalam kurun 22 bulan, Sedangkan dengan akad Ijarah Multijasa ini jumlah nasabah pembiaayaan haji terdapat 42 nasabah hanya dalam kurun 14 bulan. Hal ini dikarenakan marketing dan semua pelaksana merasa nyaman dan tidak ragu lagi tentang ke-"syariah"an akad ini, bisa menjelaskan dengan gamblang akad-akad syariahnya. Dimana sudah jelas manfaat jasa yang di-ijarah-kan.

\subsection{Pelaksanaan Pembiayaan Talangan Haji di KSPPS BTM Mulia 2.}

\subsubsection{Pelaksanaan Pembiayaan Talangan Haji di KSPPS BTM Mulia dengan akad Qardh}

1) Persyaratan Pembiayaan Talangan Haji di KSPPS BTM Mulia

a) Cukup umur

b) Berpenghasilan

c) Membuka tabungan haji di KSPPS BTM Mulia sebesar Rp. 4.500.000,untuk setiap 1 porsi haji

d) Foto copy KTP suami-istri

e) Foto copy Kartu Keluarga

f) Foto copy surat nikah

g) Foto copy akte kelahiran/ijaza

h) Tes kesehatan (golongan darah, tinggi badan dan berat badan)

i) Pas Foto 80\%: $3 \times 4$ sebanyak 17 lembar, 4x6 sebanyak 3 lembar

j) Slip gaji bila ada

2) Proses dan Prosedur Pembiayaan Qardh wal Ijaroh

a) Pengajuan dari nasabah dengan mengisi form permohonan pembiayaan dan melampirkan berkasberkas syarat administratif

b) Nasabah membuka rekening tabungan haji di KSPPS BTM Mulia serta menyetorkan ujrah ke rekening tersebut sebesar Rp. 5.500.000,-

c) Survey lapangan oleh marketing terkait kredibilitas dan kemampuan bayar nasabah

d) Pengajuan persetujuan ke pengurus KSPPS BTM Mulia.

e) Setelah persetujuan pengurus keluar, maka proses pencairan dilakukan yaitu dilakukan dengan cara :

1) KSPPS BTM Mulia bersama nasabah melakukan dan menandatangani akad / perjanjian Al-Qardh 
2) Selanjutnya nasabah diminta membuka rekening tabungan haji di bank yang ditunjuk oleh KSPPS BTM Mulia, kemudian dana akan ditransfer ke rekening haji milik nasabah tersebut sebesar Rp. 25.000.000,-

f) Pemberkasan Haji di Depag dilakukan sendiri oleh Nasabah

g) Buku tabungan dan porsi pendaftaran haji dari kementrian agama selanjutnya digunakan sebagai Jaminan (Kafalah).

Kafalah dilakukan dengan cara menandatangani beberapa surat kuasa dan surat pernyataan diantaranya :

o Surat pernyataan pengunduran diri sebagai calon jamaah haji

o Surat kuasa pendebetan rekening tabungan haji di KSPPS BTM Mulia

o Surat kuasa pendebetan rekening tabungan haji di perbankan Syariah umum

o Surat kuasa khusus guna pengurusan segala hal terkait pengurusan haji

o Surat permohonan pembatalan serta pengembalian dana setoran $\mathrm{BPIH}$ Tabungan yang ditujukan kepada Kepala Kantor Departemen Agama RI

\subsubsection{Pelaksanaan pembiayaan Talangan Haji di KSPPS BTM Mulia dengan akad Ijarah MultiJasa}

1) Syarat dan Rukun Pembiayaan

a) Cukup umur

b) Berpenghasilan

c) Membuka tabungan haji di KSPPS BTM Mulia dan menyetorkan dana di awal dengan ketentuan :

1) Rp. 4.500.000,- untuk 1 porsi haji

2) Rp. $7.000 .000,-$ untuk 2 porsi

3) Rp. 9.500 .000 ,- untuk 3 porsi haji
4) Rp. 12.000.000,- untuk 4 porsi haji

d) Foto copy KTP suami-istri

e) Foto copy Kartu Keluarga

f) Foto copy surat nikah

g) Foto copy akte kelahiran/ijazah

h) Tes kesehatan (golongan darah, tinggi badan dan berat badan)

i) Pas Foto $80 \%$ : $3 \times 4$ dan $4 \times 6$

j) Slip gaji bila ada

2) Proses dan Prosedur Pembiayaan

a) Pengajuan dari nasabah dengan mengisi form permohonan pembiayaan (lampiran 9.1) dan melampirkan berkas-berkas syarat administratiF

b) Nasabah membuka rekening tabungan haji di KSPPS BTM Mulia sebagaimana ketentuan di atas yaitu sebesar :

1) Rp. 4.500 .000 ,- untuk 1 porsi haji

2) Rp. 7.000.000,- untuk 2 porsi

3) Rp. 9.500.000,- untuk 3 porsi haji

4) Rp. 12.000.000,- untuk 4 porsi haji

c) Survey lapangan oleh marketing terkait kredibilitas dan kemampuan bayar nasabah

d) Pengajuan persetujuan ke pengurus KSPPS BTM Mulia.

e) Setelah persetujuan pengurus keluar, maka proses pencairan dilakukan yaitu dilakukan dengan cara :

1) KSPPS BTM Mulia bersama nasabah melakukan dan menandatangani akad / perjanjian Al-Ijarah Multijasa

2) Selanjutnya nasabah diminta membuka rekening tabungan haji di bank yang ditunjuk oleh KSPPS BTM Mulia sebesar Rp. 3.000.000,- dengan uang pribadinya, kemudian dana akan ditransfer ke rekening haji milik 
nasabah tersebut sebesar Rp. 22.000.000,-

f) Pemberkasan Haji di Kementrian Agama, nasabah akan didampingi dan difasilitasi oleh KSPPS BTM Mulia. Termasuk di dalamnya transport, akomodasi serta biaya-biaya yang keluar saat pemberkasan di Kementrian Agama di tanggung oleh KSPPS BTM Mulia

g) Buku tabungan dan porsi pendaftaran haji dari kementrian agama selanjutnya digunakan sebagai Jaminan (Kafalah).

Kafalah dilakukan dengan cara menandatangani beberapa surat kuasa dan surat pernyataan diantaranya :

$\checkmark$ Surat pernyataan pengunduran diri sebagai calon jamaah haji (lampiran 9.4)

$\checkmark$ Surat kuasa pendebetan rekening tabungan haji di KSPPS BTM Mulia (lampiran 9.5)

$\checkmark$ Surat kuasa pendebetan rekening tabungan haji di perbankan Syariah umum

$\checkmark$ Surat kuasa khusus guna pengurusan segala hal terkait pengurusan haji

$\checkmark$ Surat permohonan pembatalan serta pengembalian dana setoran BPIH Tabungan yang ditujukan kepada Kepala Kantor Departemen Agama RI

Berdasar data - data penelitian yang termuat di atas maka penulis akan menelaah implementasi pembiayaan talangan haji di KSPPS BTM Mulia ditinjau dari Hukum Ekonomi Syariah yang berlaku di Indonesia, dalam hal ini adalah Fatwa-Fatwa dari Dewan Syariah Nasional (DSN) Majelis Ulama Indonesia (MUI). Pembahasan akan kami bagi dalam dua masalah; yakni implementasi dengan menggunakan akad qardh bil ujrah dan implementasi dengan menggunakan akad Ijarah Multijasa.

\subsection{Tinjauan Syariah atas Akad Pembiayaan Talangan Haji.}

\subsubsection{Pembiayaan Talangan Haji dengan akad Qardh}

Untuk mengetahui sudah sesuaikah implementasi pembiayaan talangan haji dengan akad qardh di KSPPS BTM Mulia ini, kita perlu mengetahui proses dan prosedur yang dilakukan Nasabah dan pihak BTM Mulia, mulai dari permohonan pembiayaan sampai selesainya pendaftaran di Kementrian Agama untuk mendapatkan porsi haji.

Seseorang yang ingin mendaftarkan haji dan belum memiliki dana yang cukup mendatangi KSPPS BTM Mulia untuk mengajukan pembiayaan haji. Setelah dilakukan survey dan disetujui pembiayaannya, Selanjutnya yang bersangkutan membuka rekening Rekening wadi'ah di KSPPS BTM Mulia serta menyetorkan biaya administrasi ke rekening tersebut sebesar Rp. 5.500.000,-. selanjutnya ditandatanganilah perjanjian Al-Qardh antara KSPPS BTM Mulia (Muqridh) dan Nasabah pembiayaan haji (Muqtaridh). Dengan ditandatanganinya perjanjian qardh, maka nasabah (muqtaridh) akan menerima dana pembiayaan sebesar Rp. 25.000.000,dengan disetornya dana oleh KSPPS BTM Mulia ke rekening tabungan haji nasabah yang ada di perbankan Syariah Umum. Di mana sebelumnya Nasabah didampingi petugas dari KSPPS BTM Mulia membuka tabungan haji di bank syariah yang ditunjuk oleh KSPPS BTM Mulia, buku tabungan dibawa oleh petugas dari KSPPS BTM Mulia. Selanjutnya nasabah secara mandiri mengurus proses pemberkasan haji di Kementrian Agama hingga keluar "porsi haji". Proses berikutnya adalah kafalah, yakni nasabah menjaminkan berkas berkas 
haji yang ada yaitu buku tabungan haji, berkas pendaftaran haji dari Kementrian Agama dan dilampirkan beberapa surat pernyataan sebagaimana paparan data sebelumnya.

Dari perjanjian al-qardh ini selanjutnya untuk setiap bulannya sampai 36 bulan berikutnya nasabah (muqtaridh) diwajibkan membayar cicilan sebesar Rp. 694.445,untuk tiap 1 porsi haji. Atau kali dikalikan jumlah pembayaran sampai 36 bulan adalah Rp. 25.000.000,-

Pada perjanjian ini nasabah (muqtaridh) menerima dana pembiayaan sebesar $\mathrm{Rp}$. 50.000.000,- dengan menjaminkan : bukti setor BPIH, surat pernyataan batal dari jamaah, surat permohonan batal dari jamaah kepada Kandepag, Surat kuasa dari jamaah kepada koperasi untuk mengurus pembatalan. Selanjutnya pada pasal 5 perjanjian ini muqtaridh diwajibkan membayaran cicilan per bulannya sebesar Rp. 1.388.888,-. Pada perjanjian ini tertuang, muqtaridh diwajibkan membayar biaya adminitrasi sebesar Rp. 11.000.000,- (untuk 2 porsi haji). Dalam perjanjian ini peneliti tidak menemukan point yang menyebutkan adanya denda apabila terjadi keterlambatan pembayaran oleh muqtaridh.Sesuai dengan konfirmasi lesan peneliti kepada manajer operasional KSPPS BTM Mulia Saudari Ari Purwanti, KSPPS BTM Mulia memang tidak menerapkan denda pada semua nasabahnya, termasuk pada perjanjian AlQardh ini.

Untuk melihat masalah ini lebih jernih, penulis akan membandingkan proses dan prosedur pembiayaan talangan haji dengan akad Qardh ini perlu apa Fatwa DSN MUI Nomor 29/DSN-MUI/VI/2002 Tentang Pembiayaan Pengurusan Haji Lembaga Keuangan Syariah memberikan beberapa ketentuan dalam implementasinya yaitu :

a. Dalam pengurusan haji bagi nasabah, LKS dapat memperoleh imbalan jasa (ujrah) dengan dengan menggunakan prinsip al-Ijarah sesuai Fatwa DSN-MUI nomor 9/DSN-MUI/IV/2000. Apa yang dilakukan dan dikerjakan di KSPPS BTM Mulia bukanlah ujrah (jasa), karena yang tertulis di perjanjian Al-Qardh sebagaiman lampiran 8, adalah "biaya administrasi". Apabila biaya tersebut dianggap sebagai akad ijarah atau fee bagi KSPPS BTM Mulia, maka tidak jelas ditemukan manfaat dari obyek ijarah yang diterima oleh nasabah (muqtaridh). Hal ini menyalahi ketentuan yang ada pada fatwa DSN-MUI Nomor 09/DSNMUI/VI/2000 tentang akad Ijarah yang menyebutkan bahwa :

1) Obyek ijarah adalah manfaat dari penggunaan barang dan/atau jasa.

2) Manfaat barang atau jasa harus bisa dinilai dan dapat dilaksanakan dalam kontrak.

3) Manfaat barang atau jasa harus yang bersifat dibolehkan (tidak diharamkan).

4) Kesanggupan memenuhi manfaat harus nyata dan sesuai dengan syari'ah.

5) Manfaat harus dikenali secara spesifik sedemikian rupa untuk menghilangkan jahalah (ketidaktahuan) yang akan mengakibat-kan sengketa.

6) Spesifikasi manfaat harus dinyatakan dengan jelas, termasuk jangka waktunya. Bisa juga dikenali dengan spesifikasi atau identifikasi fisik.

7) Sewa atau upah adalah sesuatu yang dijanjikan dan dibayar nasabah kepada LKS sebagai pembayaran manfaat. Sesuatu yang dapat dijadikan harga dalam jual beli dapat pula dijadikan sewa atau upah dalam Ijarah.

8) Pembayaran sewa atau upah boleh berbentuk jasa (manfaat lain) dari jenis yang sama dengan obyek kontrak. Sehingga ketidakjelasan obyek ijarah ini yang menyebabkan akad ini dikatakan bathil. 
b. Apabila diperlukan, LKS dapat membantu menalangi pembayaran BPIH nasabah dengan menggunakan prinsip alQardh sesuai Fatwa DSN-MUI nomor 19/DSN-MUI/IV/2001. Ketentuan ini sudah sesuai dilakukan oleh KSPPS BTM Mulia

c. Jasa pengurusan haji yang dilakukan LKS tidak boleh dipersyaratkan dengan pemberian talangan haji. Dana Rp. 5.500.000,- yang dibayarkan di KSPPS BTM Mulia ini bukanlah jasa akan tetapi "biaya administrasi" yang dikamuflasekan sebagai "jasa"

d. Besar imbalan jasa al-Ijarah tidak boleh didasarkan pada jumlah talangan alQardh yang diberikan LKS kepada nasabah. Pada KSPPS BTM Mulia ini, dari 22 pembiayaan yang ada tidak ditemukan data perbedaan plafon kredit, maupun rentang waktu kredit, karena ke22 pembiayaan talangan haji dengan akad qardh menggunakan plafon kredit Rp. 25.000.000,- dan tempo pembiayaan 36 bulan semuanya. Akan tetapi berdasar wawancara penulis dengan Ibu Ari Purwanti selaku Manajer Operasional KSPPS BTM Mulia, disebutkan bahwa ditetapkan oleh KSPPS BTM Mulia, walaupun plafon kredit kurang dari Rp. 25.000.000,- dan jangka waktu pembiayaan kurang dari 36 bulan, biaya administrasi yang dibebankan ke nasabah tetap Rp. 5.500.000,- perbulan.

Mencermati uraian proses dan perjanjian di atas, maka menurut penulis ada beberapa hal yang menyebabkan implementasi pembiayaan Al-Qardh di KSPPS BTM Mulia ini tidak sesuai dengan hukum ekonomi syariah, sehingga menjadikan akad ini tidak halal, yaitu :

a. Besaran biaya administrasi. Jika dilihat dari besarnya biaya administrasi ini, yaitu sekitar 22\% untuk 3 tahun, atau 7,33\% pertahun, hampir sama dengn bunga pinjaman yang ditarik oleh bank konvensional. Besaran biaya ini juga tidak realistis benar-benar dikeluarkan oleh KSPPS BTM Mulia untuk pengurusan pemberkasan haji

b. Tersirat dalam proses maupun akad alqardh bahwa biaya administrasi dipersyaratkan dalam akad ini. Nasabah tidak akan bisa mendapatkan pembiayaan talangan haji, apabila tidak membayar biaya administrasi. Sehingga persyaratan inilah yang menjadikan tambahan biaya administrasi sebagai riba.Dan ini bertentangan dengan kaidah-kaidah syariat Islam yang melarang riba.

Dari semua pembahasan implementasi akad pembiayaan qardh untuk talangan haji di KSPPS BTM Mulia di atas, agar pelaksanaannya akad ini menjadi sesuai dengan kaidah-kaidah syariah, maka perlu pembenahan dan penyesuaian beberapa hal, yaitu :

a. Hendaknya di akad qardh yang ada ini tidak mencantumkan biaya administrasi yang nominalnya tidak wajar dan secara realita tidak dikeluarkan dalam proses akad/perjanjian ini.

b. Sebagai ganti "biaya administrasi" sebagaimana yang ada di perjanjian sebelumnya, maka perlu dibuatkan lagi akad Al-Ijarah, yaitu terkait ujrah/upah untuk jasa pengurusan perolehan porsi haji, dengan syarat KSPPS BTM Mulia nyata-nyata memfasilitasi dan melakukan usaha untuk pekerjaan pengurusan tersebut.

c. Besarnya ujrah tidak dipersyaratkan berdasar waktu pembiayaan ataupun jumlah talangan haji yang menggunakan akad qardh.

\subsubsection{Pembiayaan Talangan Haji dengan akad Ijarah Multijasa}

Untuk mengetahui sudah sesuaikah implementasi pembiayaan talangan haji dengan akad ijarah multijasa di KSPPS BTM Mulia ini, kita perlu mengetahui 
proses dan prosedur yang dilakukan Nasabah dan pihak BTM Mulia, mulai dari permohonan pembiayaan sampai selesainya pendaftaran di Kementrian Agama untuk mendapatkan porsi haji.

Seseorang yang ingin mendaftarkan haji dan belum memiliki dana yang cukup mendatangi KSPPS BTM Mulia untuk mengajukan pembiayaan haji. Setelah dilakukan survey dan disetujui pembiayaannya, Selanjutnya yang bersangkutan membuka rekening Rekening wadi'ah di KSPPS BTM Mulia serta menyetorkan ujrah atau fee/upah pengurusan haji dengan ketentuan sebagaiman yang disebutkan di atas yaitu Rp. 4.500.000,untuk 1 porsi haji, Rp. 7.000.000,- untuk 2 porsi, Rp. 9.500.000,- untuk 3 porsi haji, Rp. 12.000.000,- untuk 4 porsi haji. Selanjutnya ditandatanganilah perjanjian Ijarah Multijasa antara KSPPS BTM Mulia sebagai Pemberi Jasa (Mu'jir) dan Nasabah pembiayaan haji sebagai Pengguna Jasa (Musta'jir). Dengan ditandatanganinya perjanjian ijarah multijasa ini, maka telah disepakati bahwa nasabah sebagai pengguna/penerima jasa (musta'jir), memberikan pekerjaan kepada KSPPS BTM Mulia sebagai Pemberi Jasa (Mu'jir) untuk kebutuhan pembayaran Biaya Perjalan Ibadah Haji (BPIH) bagi nasabah. Atas kesepakatan ijarah multijasa ini, Mu'jir akan memberikan talangan pembayaran ke tabungan haji milik nasabah (musta'jir) di bank syariah umum sebesar Rp. 44.000.000,- untuk 2 orang (atau Rp. 22.000.000 untuk 1 orang). Atas kesepakatan ijarah multijasa ini pula nasabah (musta'jir) berkewajiban membayarkan ujrah guna pembayaran Biaya Perjalan Ibadah Haji (BPIH) sebesar Rp. 18.600.000 untuk 2 orang.

Proses selanjutnya adalah Nasabah (musta'jir) difasilitasi penuh oleh KSPPS BTM Mulia guna pengurusan porsi haji, mulai dari pemberkasan; foto dan test kesehatan; pembukaan rekening tabungan haji di bank syariah umum; pegurusan permohonan porsi haji ke Kementrian Agama sampai keluar porsi haji. Munculnya biaya-biaya yang keluar dalam proses ini menjadi tanggungan KSPPS BTM Mulia sebagai pember jasa (mu'jir). Biaya-biaya yang riil keluar dalam proses ini antara lain materai, foto dan test keshatan, sewa kendaran guna pengurusan porsi ke Kementrian Agama, konsumsi dan biayabiaya tak terduga lain yang mungkin muncul saat pengurusan porsi haji.

Setelah nasabah memperoleh porsi haji dari Kementrian Agama, proses berikutnya adalah kafalah, yakni nasabah menjaminkan berkas berkas haji yang ada yaitu buku tabungan haji, berkas pendaftaran haji dari Kementrian Agama dan dilampirkan beberapa surat pernyataan.

Dalam Penelitian ini, penulis juga menggali informasi apakah ada perlakuan berbeda dalam perhitaungan apabila terdapat perubahan waktu pembiayaan, jumlah nasabah pembiayaan atau uang muka yang dibayarkan oleh nasabah (musta'jir). Penulis menggali informasi ini kepada saudari Ari Purwanti selaku manajer KSPPS BTM Mulia, hasilnya dapat penulis sajikan dalam tabel berikut:

Gambar 3.4

Perhitungan Pembiayaan Haji dengan Akad Ijarah Multijasa

\begin{tabular}{|l|r|r|r|r|}
\hline $\begin{array}{c}\text { Jumlah } \\
\text { Peserta Haji }\end{array}$ & \multicolumn{1}{c|}{ 1 orang } & 2 orang & 3 orang & 4 orang \\
\hline Porsi Haji & 25.000 .000 & 50.000 .000 & 75.000 .000 & 100.000 .000 \\
\hline Plafon talangan & 22.000 .000 & 44.000 .000 & 66.000 .000 & 88.000 .000 \\
\hline Ujrah & 8.100 .000 & 16.200 .000 & 24.300 .000 & 32.400 .000 \\
\hline $\begin{array}{l}\text { Uang muka } \\
\text { (DP) } \\
\text { pembayaran }\end{array}$ & 4.500 .000 & 7.000 .000 & 9.500 .000 & 12.000 .000 \\
\hline $\begin{array}{l}\text { Penggunaan } \\
\text { uang muka }\end{array}$ & 3.000 .000 & 6.000 .000 & 9.000 .000 & 12.000 .000 \\
\hline $\begin{array}{l}\text { Pembukaan } \\
\text { rekening haji }\end{array}$ & 1.500 .000 & 1.000 .000 & 500.000 & \\
\hline $\begin{array}{l}\text { Sisa DP Setelah } \\
\text { pembukaan rek. }\end{array}$ & $(600.000)$ & $(900.000)$ & $(1.350 .000)$ & $(1.700 .000)$ \\
\hline $\begin{array}{l}\text { biaya } \\
\text { administrasi }\end{array}$ & 900.000 & 100.000 & $(850.000)$ & $(1.700 .000)$ \\
\hline sisa lebih & & & & \\
\hline
\end{tabular}




\begin{tabular}{|l|r|r|r|r|}
\hline $\begin{array}{l}\text { (kurang) uang } \\
\text { muka haji }\end{array}$ & 7.200.000 & 16.100 .000 & 25.150 .000 & 34.100 .000 \\
\hline $\begin{array}{l}\text { sisa } \text { ujrah } \\
\text { dipotong } \\
\text { kelebihan uang } \\
\text { muka }\end{array}$ & 200.000 & 447.222 & 698.611 & 947.222 \\
\hline $\begin{array}{l}\text { cicilan } \text { ujrah } \\
\text { perbulan }(36 \\
\text { bulan) }\end{array}$ & 611.111 & 1.222 .222 & 1.833 .333 & 2.444 .444 \\
\hline $\begin{array}{l}\text { Cicilan plafon } \\
\text { talangan haji } \\
\text { (36 bulan) }\end{array}$ & $\mathbf{8 1 1 . 1 1 1}$ & $\mathbf{1 . 6 6 9 . 4 4 4}$ & $\mathbf{2 . 5 3 1 . 9 4 4}$ & $\mathbf{3 . 3 9 1 . 6 6 7}$ \\
\hline $\begin{array}{l}\text { Total Cicilan } \\
\text { per bulan }\end{array}$ & & & & \\
\hline
\end{tabular}

Apabila dihitung perorang nasabah, tidak ditemukan perubahan ujrah apabila terdapat jumlah nasabah yang berbeda baik1 orang, 2 orang , 3 orang mauupun 4 otrang. Perbedaan jumlah cicilan ujroh dikarenakan perbedaan biaya administrasi riil yang dikeluarkan oleh KSPPS BTM Mulia. Sebagaimana yang bisa dilihat dari dokumen gambar berikut :

Gambar 3.5

Rincian Biaya Administrasi

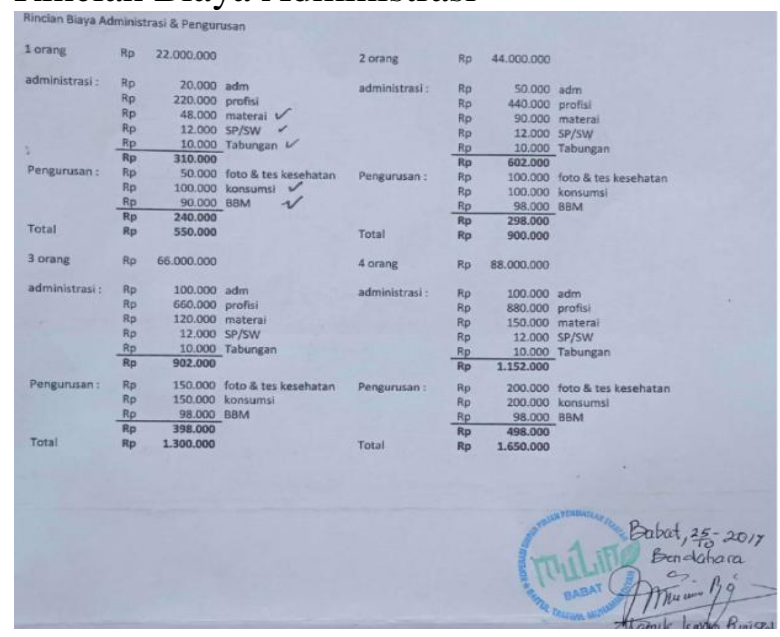

Besaran uang muka (DP) pembayaran talangan haji apabila dicermati ternyata juga tidak berpengaruh terhadap jumlah ujroh. Hal ini merupakan trik marketing dari KSPPS BTM Mulia guna meringankan calan nasabah yang akan menggunakan dana talangan haji, karena semakin banyak nasabah dalam satu akad secara variable jumlah DP yang dikelurakan juga semakin sedikit.
Menganalisa apakah proses dan prosedur pembiayaan haji dengan akad ijarah multijasa ini sudah sesuai dengan kaidahkaidah syariat islam yang ada, terutama hukum ekonomi Islam yang di akui, yakni Fatwa-fatwa DSN-MUI, dapat penulis paparkan terlebih dahulu beberapa ketentuan dari fatwa-fatwa DSN-MUI terkait pembiayaan Multijasa ini, yaitu :

Fatwa DSN MUI Nomor 44/DSNMUI/VIII/2004 Tentang Pembiayaan Multijasa memberikan beberapa ketentuan dalam implementasinya yaitu :

a. Pembiayaan Multijasa hukumnya boleh (ja`iz) dengan menggunakan akad Ijarah atau Kafalah.

b. Dalam hal LKS menggunakan akad ijarah, maka harus mengikuti semua ketentuan yang ada dalam Fatwa Ijarah.

c. Dalam hal LKS menggunakan akad Kafalah, maka harus mengikuti semua ketentuan yang ada dalam Fatwa Kafalah.

d. Dalam kedua pembiayaan multijasa tersebut, LKS dapat memperoleh imbalan jasa (ujrah) atau fee. Besar ujrah atau fee harus disepakati di awal dan dinyatakan dalam bentuk nominal bukan dalam bentuk prosentase.

Fatwa DSN MUI Nomor 09/DSNMUI/VI/2000 Tentang Pembiayaan Ijarah memberikan beberapa ketentuan dalam implementasinya yaitu

a. Obyek ijarah adalah manfaat dari penggunaan barang dan/atau jasa.

b. Manfaat barang atau jasa harus bisa dinilai dan dapat dilaksanakan dalam kontrak.

c. Manfaat barang atau jasa harus yang bersifat dibolehkan (tidak diharamkan).

d. Kesanggupan memenuhi manfaat harus nyata dan sesuai dengan syari'ah.

e. Manfaat harus dikenali secara spesifik sedemikian rupa untuk menghilangkan jahalah (ketidaktahuan) yang akan mengakibatkan sengketa. 
f. Spesifikasi manfaat harus dinyatakan dengan jelas, termasuk jangka waktunya. Bisa juga dikenali dengan spesifikasi atau identifikasi fisik.

g. Sewa atau upah adalah sesuatu yang dijanjikan dan dibayar nasabah kepada LKS sebagai pembayaran manfaat. Sesuatu yang dapat dijadikan harga dalam jual beli dapat pula dijadikan sewa atau upah dalam Ijarah.

h. Pembayaran sewa atau upah boleh berbentuk jasa (manfaat lain) dari jenis yang sama dengan obyek kontrak.

i. Kelenturan (flexibility) dalam menentukan sewa atau upah dapat diwujudkan dalam ukuran waktu, tempat dan jarak.

Fatwa DSN MUI Nomor 11/DSNMUI/VI/2000 Tentang Pembiayaan Kafalah memberikan beberapa ketentuan dalam implementasinya yaitu

a. Pernyataan ijab dan qabul harus dinyatakan oleh para pihak untuk menunjukkan kehendak mereka dalam mengadakan kontrak (akad).

b. Dalam akad kafalah, penjamin dapat menerima imbalan (fee) sepanjang tidak memberatkan.

c. Kafalah dengan imbalan bersifat mengikat dan tidak boleh dibatalkan secara sepihak.

Rukun dan Syarat Kafalah:

a. Pihak Penjamin (Kafiil)

1) Baligh (dewasa) dan berakal sehat.

2) Berhak penuh untuk melakukan tindakan hukum dalam urusan hartanya dan rela (ridha) dengan tanggungan kafalah tersebut.

b. Pihak Orang yang berutang (Ashiil, Makfuul 'anhu)

1) Sanggup menyerahkan tanggungannya (piutang) kepada penjamin.

2) Dikenal oleh penjamin.

c. Pihak Orang yang Berpiutang (Makfuul Lahu)

1) Diketahui identitasnya.
2) Dapat hadir pada waktu akad atau memberikan kuasa.

3) Berakal sehat.

d. Obyek Penjaminan (Makful Bihi)

1) Merupakan tanggungan pihak/orang yang berutang, baik berupa uang, benda, maupun pekerjaan.

2) Bisa dilaksanakan oleh penjamin.

3) Harus merupakan piutang mengikat (lazim), yang tidak mungkin hapus kecuali setelah dibayar atau dibebaskan.

4) Harus jelas nilai, jumlah dan spesifikasinya.

5) Tidak bertentangan dengan syari'ah (diharamkan).

Dari ketentuan-ketentuan di atas, baik ketentuan ijarah maupun kafalah, dapat penulis bandingkan dengan proses dan prosedur yang ada di KSPPS BTM Mulia yaitu :

a. Obyek ijarah pada perjanjian ini jelas, dapat diukur dan dapat dilaksanakan dalam kontrak yaitu Biaya Perjalan Ibadah Haji (BPIH). Dimana KSPPS BTM Mulia sebagai (Mu'jir) memberikan manfaat kepada Nasabah (Musta'jir) berupa pembukaan rekening tabungan haji dan pengurusan porsi haji, sehingga Nasabah (Musta'jir) akan mempunyai kepastian pendaftaran hajinya di Kementrian Agama Repulik Indonesia

b. Fee/imbalan/ujrah jelas dan nyata dinyatakan dalam kontrak (akad).

c. Kesanggupan memenuhi manfaat harus nyata dan sesuai dengan syari'ah juga sudah termaktub dalm kontrak

d. Akad kafalah juga sudah sesuai dengan kaida-kaidah yang ditentukan oleh DSNMUI yaitu :

$\checkmark$ obyek kafalah yang jelas yaitu buku tabungan haji dan porsi haji dari kementrian Agama

$\checkmark$ Bisa dilaksanakan oleh penjamin dan mengikat, yaitu diikat dengan beberapa surat pernyataan. 
Berdasar uraian di atas, pembiayaan talangan haji yang menggunakan akad ijarah multijasa lebih sesuai dan mendekati kaidahkaidah Syariat Islam. Hal ini dikarenakan Obyek ijarah adalah jelas dan nyata adanya, yaitu fasilitas pengurusan proses pendaftaran haji mulai dari pembukaan rekening haji di bank syariah umum, pemberkasan di Kementrian Agama sampai dengan nasabah mempunya porsi haji. Ujrah yang diminta oleh KSPPS BTM Mulia kepada nasabah wajar dan nasabah benar-benar mendapatkan manfaat dari akad multijasa ini yaitu manfaat jasa pengurusan porsi haji.

\section{Kesimpulan}

Dari penelitian ini diketahui bahwa implementasi pembiayaan talangan haji di KSPPS BTM Mulia yang menggunakan akad qardh tidak bisa dijamin kehalalannya hal ini desebabkan karena pengenaan biaya administrasi yang tidak wajar yaitu sebesar Rp. 5.500.000,- per porsi haji. Padahal KSPPS BTM Mulia tidak pada proses akad qardh untuk pembiayaan hajinya tidak mengeluarkan biaya administrasi sebesar itu. Apalagi dalam proses pengurusan haji, KSPPS BTM Mulia juga tidak melakukan kegiatan apapun atau memberikan manfaar apapun baik manfaat barang atau manfaat jasa kepada nasabah pembiayaan talangan haji. Jadi jelaslah biaya administrasi sebesar Rp. 5.500.000,- merupakan kamuflase dari riba qardh.

Pada pembiayaan talangan haji yang menggunakan akad ijarah Multijasa berdasar penelitian ini lebih sesuai dan mendekati kaidah-kaidah Syariat Islam. Hal ini dikarenakan Obyek ijarah adalah jelas dan nyata adanya, yaitu fasilitas pengurusan proses pendaftaran haji mulai dari pembukaan rekening haji di bank syariah umum, pemberkasan di Kementrian Agama sampai dengan nasabah mempunya porsi haji.

Ujrah yang diminta oleh KSPPS BTM Mulia kepada nasabah wajar dan nasabah benar-benar mendapatkan manfaat dari akad multijasa ini yaitu manfaat jasa pengurusan porsi haji.

Beberapa saran dapat penulis sampaikan sebagai berikut :

Untuk Lembaga Keuangan Syariah agar benar-benar menerapkan fatwa - fatwa yang ada di DSN-MUI secara cermat dan hati-hati agar tidak keluar dari rel dan garis yang ada sehingga terjebak dalam praktek riba, gharar dan bathil dalam transaksinya.

Agar Lembaga Keuangan Syariah menarik biaya administrasi yang wajar dan nyata-nyata diperlukan dengan besaran biaya yang tetap, tidak berdasarkan besarnya pinjaman.

Untuk DSN-MUI selain mengeluarkan fatwa, diharpkan dapat memberikan petunjuk teknis pelaksanaannya dan diharapkan bisa memberikan pengawasan dan sanksi bagi lembaga-lembaga keuangan syariah yang menerapkan produk-produk fatwa DSN-MUI tidak sesuai dengan fatwa tersebut.

\section{DAFTAR PUSTAKA}

Darsono, Ferry Syaifuddin, Ali Sakti, Enny Tin Suryanti, Peta Keuangan Mikro Syariah Indonesia, (Jakarta: Tazkia, 2018)

www.ojk.go.id/id/kanal/perbankan/regulasi/peraturan-bank indonesia/Pages/peraturan-bankindonesia-nomor-11-2-pbi-2009.aspx

https://haji.kemenag.go.id/v3/basisdata/waiting-list

https://dsnmui.or.id/kategori/fatwa/ 
Undang-Undang Republik Indonesia Nomor 10 Tahun 1998 Tentang Perubahan Atas UndangUndang Nomor 7 Tahun 1992 Tentang Perbankan

Peraturan Menteri Agama Republik Indonesia Nomor 30 Tahun 2013 Tentang Bank Penerima Setoran Biaya Penyelenggaraan Ibadah Haji

Fatwa DSN-MUI Nomor: 29/DSN-MUI/VI/2002 Tentang Pembiayaan Pengurusan Haji Lembaga Keuangan Syariah

Fatwa DSN-MUI Nomor: 44/DSN-MUI/ VIII/2004 Tentang Pembiayaan Multijasa

Adib Bisri dan Munawwir, Kamus Al Bisri Arab-Indonesia Indonesia-Arab, (Surabaya: Pustaka Progressif, 1999)

Muhammad Ridwan, Manajemen BMT, (Yogyakarta: UII Press, 2004)

Widyaningsih, Bank Dan Asuransi Islam Di Indonesia, (Jakarta, Prenada Media, 2005)

fatwa Dewan Syariah Nasional Nomor 19/DSN-MUI/IV/2001 Tentang Al-Qardh

Sri Nurhayati dan Wasilah, Akuntansi Syariah Di Indonesia, (Edisi 3, Jakarta: Salemba Empat, 2013)

Muhammad, Model-Model Akad Pembiayaan di Bank Syariah, (Yogyakarta: UII Press, 2009) 